desiccated fat-free substances of a cow's corpus luteum into a laying fowl at once inhibits ovulation. The possible practical importance of studies in heredity is shown by a short pamphlet from the annual report of the Maine Agricultural Experiment Station for I914 on improving, egg-production by breeding, and by a Bulletin (No. r ro) of the U.S. Department of Agriculture (Bureau of Animal Industry), in which Dr. Pearl, with Dr. F. M. Surface, gives "A Biometrical Study of Egg-Production in the Domestic Fowl."

\section{BACK TO LISTER. 1}

WHEN Sir James Crichton-Browne, amongst whose many charms is a singular félicity of phraseology, invited me to undertake this task, he kindly supplied the title. It sounded rather startling, but as I could not think of a better, I humbly accepted it. It shows that I have no great discovery to announce, no new theory to propound, but only to take you back over old, well-trodden ground, to try to interest you in very technical matters, and to suggest that, in this particular case, reaction has overstepped the bounds of moderation, and that, as in many other fields, the most modern ideas are not always the best.

I will not trace the various steps by which Lister was led to his conclusions about the causes of suppuration and hospital diseases, nor draw a lurid picture of the deplorable mortality from these diseases before the introduction of the antiseptic system of treatment. I must, however, give you a short account of his first antiseptic method, which was founded on the discoveries of Pasteur, and explain in what way and for what reasons he afterwards modified it. If I succeed in making this clear it will be easy to understand how the relinquishment of much that he at first considered essential, but which later discoveries proved to be superfluous, led others to give up still more -much more than he ever considered it prudent to do. It will then be maintained that what he feared has come true: that the results obtained to-day, good though they are, are not so good as they would be if we were to return, perhaps not altogether, but almost, to those simpler and safer methods which Lister employed at the end of his active career.

Let us begin by trying to place ourselves in Lister's position during the years preceding $186_{5}$, when the writings of Pasteur were first brought to his notice. It was that of every thoughtful surgeon in those days. Of all the dealings of Providence with men-remember I am speaking of sixty years ago-not the least mysterious appeared to be the ordinance that the lifegiving air, heaven's blessed breeze, without which life cannot be maintained for more than a few minutes, and on the purity of which man's vigour depends, should carry in some unexplained way the seeds of death and disease, being one day the doctor's greatest friend and the next his deadliest foe.

Physicians were quite sure that the acute specific fevers, such as scarlet fever and measles, were carried on the wings of the wind, and few had any doubt that cholera was borne by the same vehicle. Surgeons were equally certain that erysipelas should be placed in the same class as the acute specific fevers and that the suppuration of wounds depended upon the same agency. It seemed quite obvious, to anyone who thought about the difference in the behaviour of simple and compound fractures, that is, fractures with unbroken skin and those which are complicated by the presence of a wound. Except for this complication the fractures might be identical, but, in pre-antiseptic 1 Disconrse delivered at the Royal Institution on Friday, March Iz, by Sir R. J. Godlee, Bart., K.C.V.O.

$$
\text { NO. } 237 \mathrm{I} \text {, VOL. 95] }
$$

days, the presence of a wound was almost certain to lead to suppuration of a serious, if not a dangerous nature.

Old Glasgow students speak of Lister contemplating a simple fracture of the leg; the muscles torn and pulped, the limb swollen and shiny, black and blue, and pointing out to them that all this destruction of tissue and extravasation of blood would be surely and safely dealt with by the kindly influences of nature; but that the admission of the air through the smallest wound in the skin would completely change the prospect; the extravasated blood would soon stink, the injured tissues-bone and muscle-would die, and suppuration would take place, which might possibly infect the whole system. It did not enter into the mind of anyone, therefore, to doubt the morbific influence of the air. It was one of those things which appear so obvious that for a time they form the very foundations of belief, such as that the earth is flat and that the sun rises, matters which in more barbarous times laid sceptics open to the rigours of the Inquisition.

This was still the universal belief when Pasteur's discoveries were made known. Pasteur put the finishing touch to the work of many observers, who, during the first half of the last century, had been striving to find out what there was in the atmosphere which gave rise to fermentations of all sorts, and amongst others to that form of fermentation known as putrefaction. So long as fermentation and putrefaction were looked upon as chemical processes it was natural to suppose that one of the gaseous constituents of the air was the cause. But clear thinkers, like John Hunter, saw that this could not be the case.

There are two surgical conditions that prove this:-

(I) If a rib be broken and a sharp fragment injures the lung, large quantities of air may pass from the lung into the pleural cavity, but if the lung be healthy, decomposition never occurs in the putrescible fluid that is always present in the pleura in small quantity.

(2) If air passes into the cellular tissue of the body, as it sometimes does after the same accident, or some other injury of the air passages, large portions of the body may be distended by it to an extent that appears alarming. But again, as the air is effectually filtered on the way, decomposition does not occur and the evil result is only a temporary mechanical one.

Investigators, therefore, began to think that the cause of fermentation must be something solid and possibly living; something so small that it eluded their highest magnifying glasses, and so they adopted different lines of attack

Some calcined the air, some filtered it, some passed it through causic fluids. There was an old French confectioner named Appert-Citoyen Appert, in the time of the Republic, who anticipated by many years the work of our modern fruit preservers. He succeeded in preserving all sorts of food in well-corked bottles by boiling them for various lengths of time according to the particular article he was dealing with; and his results were so nearly uniform and so remarkable, from an economic as well as from a scientific point of view, that they attracted the attention of the French Minister of the Interior in I8Io, and also of the Académie Française.

Unscientific as these observations were, they gave an impetus to the work of chemists and biologists who carried out an enormous number of really scientific investigations in consequence. These were repeated by Pasteur, who made countless others of his own, of marvellous ingenuity. The results of his labours in this particular field before $186_{5}$ may be given in a tabular form. He showed that :-

(I) Putrefaction is a species of fermentation. 
(2) It is caused by the growth of micro-organisms and.does not. occur independently of them.

(3) The micro-organisms that produce fermentation and putrefaction are conveyed by the air on the dust that floats in it.

(4) These micro-organisms can be destroyed by heat and other agencies, or separated by filtration.

(5) Certain recognisable organisms produce definite and distinct fermentative processes.

(6) All of these organisms require oxygren. Some of them flourish only in the presence of tree oxygen (aerobic), others only in its absence (anaerobic). The latter acquire their oxygen from the bodies which, by their growth, they are causing to ferment or putrefy.

(7) Many natural animal and vegetable products have no tendency to ferment or putrefy even in the presence of oxygen, if collected with proper precautions and kept in sterilised vessels.

(8) Spontaneous generation has never been observed to occur, and thus may be regarded as a chimera.

Now it will be observed that Pasteur's work presented Lister with two great fundamental facts.

(I) That putrefaction is caused by germs which can be destroyed by heat and chemicals and separated by filtration.

(2) That germs are carried by the dust in the air.

It is true that both Pasteur and Lister did not fail to recognise that if the air. carried the germs it must deposit them upon the surface of everything, and that therefore the surface of every solid and the whole of every liquid must be, or might be, infectious. It is also true that Lister bore this in mind, and acted on the assumption that it was true from the very first. But still it was the air to which he paid and directed most attention-more attention, as we shall see, than it deserved. He probably did not recognise, he certainly did not say, that his precautions with regard to other sources of infection were far more important than those which he tools with regard to infection from the air.

The sceptics and cavillers, the believers in spontaneous generation, kept saying, "Show us your germs in the air." They did not doubt that organisms were found in putrefying substances, they could. not do that; but they said that they might be accidental, the result of putrefaction, not the cause of it, and asked for proof that germs existed in the air. Pasteur had tried to meet this objection by filtering the air through gun-cotton, which he afterwards dissolved and submitted the solution to the microscope. There were certainly objects which he was satisfied were germs, but the doubters were still unconvinced.

A few years later, about 1860 , John Tyndall, whose eloquent addresses on "Dust and Disease" were listened to with breathless attention in this hall, succeeded in showing to the naked eye of untrained amateurs, the existence of, and the amount of, floating dust in any given sample of air, by passing through it a concentrated beam of light. Next he showed that, if the air was left undisturbed, say in a glass flask, the dust settled, and there was nothing for the beam to illuminate. Then he produced the same result by filtering the air, or by raising to a great heat a piece of platinum wire passing through the flask which burned up the dust. Finally, he proved, by a series of charmingly simple experiments, that what he called optically pure air was incapable of setting up decomposition in putrescible fluids, whereas optically impure air invariably caused them to decompose.

Most of these facts were known to Lister in 1865 . All the evidence pointed in the same direction; and therefore, stated in the simplest way, the problem seemed to be to kill the germs which might have gained access to the wound before it came under

NO. $237 \mathrm{I}$, VOL. 95] treatment, and to prevent the air from carrying in others afterwards.

He first applied what he now called the antiseptic principle to compound fractures, injuries which, above all others, were liable to be followed by those hospital plagues-pyæmia, erysipelas, and hospital gangrene.

He had to choose between the three recognised methods of excluding the germs-filtration, calcining, and chemical antiseptics-mand he naturally selected the last as the most convenient. The first antiseptic he tried was carbolic acid, and as the crude sample he first worked with was insoluble in water he used it undiluted.

His plan for treating compound fractures was, after cleansing the wound, to sponge the whole of the raw surface with this undiluted crude German creosote in order to destroy the germs introduced by dirt or other foreign material at the time of the accident, or that, as he supposed, had been carried to it by the air. The carbolic acid mixed with the blood, caused an antiseptic crust, which he fortified by covering it with a thin piece of block-tin, and this crust effectually prevented the access of unpurified air to the wound; for he left it undisturbed for days or weeks and painted the outside with more of the undiluted acid from time to time.

I wish to impress upon you that in the earliest dressings he used a very strong antiseptic and did his best absolutely to exclude the air, and it is important to note that his results were strikingly good, in spite of the fact that the undiluted acid did actually cause a certain amount of superficial sloughing-or death of the tissues-in the parts to which it was applied. As time went on a purer carbolic acid was obtained which dissolved in water, so he abandoned the caustic undiluted acid in favour of a saturated watery solution: I part to 20 .

He soon extended the treatment, first to abscesses and then to ordinary operation wounds. The old antiseptic crust was soon given up, and various dressings containing carbolic acid or other antiseptics were employed instead. But for a long time he was so anxious about the air that he irrigated the wound with a solution of carbolic acid in water throughout an operation, and took the most elaborate precautions against allowing any air that had not been submitted to the influence of carbolic acid to reach the wound at the changing of the dressings. He used to say that merely taking out a drainage tube without antiseptic precautions involved a serious risk, because the air which rushed in to take its place might carry some speck of dust and a germ along with it.

In his most palmy days, when he was professor of clinical surgery at Edinburgh (1869-77), and Edinburgh was for the time the surgeon's Mecca, he introduced the spray in order to deal still more effectually with the air. In its most highly developed form the steam spray-producer threw a copious vapour, which was supposed to contain one part of carbolic acid in forty of water, that surrounded the whole region of the operation, and, if the room were small, might even fill the whole apartment with a pungent vapour, to the great discomfort of all concerned. He thought at the time that the momentary contact of the dust with the particles of carbolised water in the spray, or the carbolised atmosphere between the drops would be enough to destroy the germs; but in after years he owned that such a result was impossible.

At this period, though he was still using strong antiseptic lotions very freely, his results were yet more remarkable; and in the meantime, relying on the antiseptic principle, he was doing new operations which, without it, he would have considered to be altogether unjustifiable. 
In spite of this, as you know, Lister's treatment, though hailed with acclamation abroad, met with a very ungenerous reception in this country. His compatriots could not: understand the great principle that underlay it. They said that there was nothing new in it, or, if there was, it was bad. They said that their results were quite as good as his, or, if they were not, it was only because he paid so much personal attention to his cases. They gave the treatment silly names, showing that they had not grasped the meaning of it ; at first it was the "carbolic treatment," now it was the "spray and gauze treatment." This last name was even adopted by Lister's disciples, and thus the spray came to be regarded as a fetish to such an extent that anything which cast a doubt upon its infallibility sorely tried the tender faith of the converted.

But increasing knowledge forced Lister to alter his own beliefs and greatly to modify his practice in the two particulars to which I have especially directed your attention. Thus he more and more diminished the strength of and the amount of his antiseptics; and, having become gradually convinced that infection from the air, far from being the greatest source of danger, was a negligible quantity, he gave up the use of the spray for good and all.

We must now inquire how this came about. Lister always looked upon an antiseptic as a necessary evil, because he saw that anything strong enough to kill germs must damage the living tissues. Therefore in quite early days he tried to do without antiseptics altogether, or at all events to admit nothing of the sort to the wound after the operation was finished. $\mathrm{He}$ also recognised from the first that healthy-living tissues had the mysterious power of preventing the growth of micro-organisms; and that this protective power was diminished by anything that lowered their vitality. He further pointed out that the vitality of the tissues varies in different individuals and in different parts of the body, as is illustrated by the well-known fact that healing takes place more readily in infancy than in old age, and in the face than in one of the limbs. The true meaning of this power was not then known. The explanation was given by the marvellous discoveries of Metchnikoff which Lister's own work prepared him to receive, when they were made known to the worid.

Everyone now is familiar with the word "phagocytosis," but have you, ladies and gentlemen, really grasped its meaning? It is a sufficiently appalling thought that each one of us, who looks upon himself as a single individual, is only a huge joint stock company. We carry about with us millions and millions of other individual organisms--micro-organisms indeed-but each one endowed at least with life and definite individual functions. Some of them are apparently essential to the success of our bodies as a going concern. Many, even of these, are only waiting for some interference with the vitality of a part, or the whole, of our body, to afflict us with local or general disease, and finally to dissolve us into our elements.

Metchnikoff showed how these malignant organisms are kept at bay. Our very own body is made up of cells, each of which has, so to say, its individual existence and its special functions-almost its special intelligence-a fact which Lister was one of the first to demonstrate. Hosts of these cells--Metchnikoff's phagocytes-form, some of them, our main mobile army of defence. They are not like other defensive cells, such as those of the spleen and bone marrow, confined to their fortresses, though as a rule, they keep their allotted positions. But they can move along strategic railways to any special point of attack, and when they have reached it, there ensues a battle NO. $237 \mathrm{I}$, VOL. 95] royal with the invading army of pathogenic organisms, which they try to swallow, and, if possible, to destroy. If they are successful, health is restored. It may mean the aborting of a cold in the head, the subsidence of a pneumonia, or the rapid healing of a cut. If, on the other hand, they are overpowered by the invaders, the catarrh may extend to the smallest bronchi, the pneumonia may end fatally, or the wound may suppurate with disastrous results.

These illuminating facts turned the attention of surgeons into another direction; and seeing that everyone knew that the vitality of the phagocytes must be impaired by any mechanical or chemical injury, the tendency was to reduce the strength of the antiseptics and to trust more and more to the phagocytes. Lister himself used weaker and weaker antiseptic lotions, but he never thought it wise to dis. pense with them altogether. Others, however, being chiefly obsessed with the notion that chemical antiseptics diminish the power of the phagocytes, maintained that their use should be altogether discontinued, and have adopted, or say they have adopted, a treatment which, though having the same object as Lister's, is supposed to be founded upon a different principle. How far this is actually the case it will presently be our business to inquire.

This was one of the reasons why it began to be said that Lister's teaching, like the Old Testament, was obsolete, and must be replaced by a newer and more perfect gospel.

We must now further consider how far the air is really a source of infection. In the early days it was said that the number of germs in the air was enornous. As a matter of fact, such a statement is still true, as is easily shown by exposing a plate of cultivating medium in any room, say in the most up-todate modern operating theatre.

It was also taken for granted that the large majority of germs were pathogenic--that is, disease producing. But very little was known, in $186_{5}$, of the varieties of micro-organisms. It is true that Pasteur had isolated various yeasts or ferments, and had shown that some organisms were aerobic and some anaerobic, and that the words vibrio and bacterium were beginning to be usied. But as time went on two very important facts were made out. First, that only a small proportion of the flora of the air are pathogenic; and, secondly (and this was one of Lister's own discoveries), that great dilution of a septic fluid very much diminished its chance of infecting a putrescible medium. Thus typhoid pollution of the Nile in a few miles ceases to be a source of danger, and one or two septic organisms introduced into a vessel of blood serum will fail to grow. It is really masses of particulate dirt which are dangerous, because they contain colonies of organisms adequately protected from attack. And, if this applies to attempts at infection of vessels containing blood serum, still more does it apply to the dropping of isolated staphylococci and streptococci on to a wound where the greedy phagocytes are lying in wait to devour them. At every operation scores of germs fall upon a wound-hundreds if it be prolonged-but most of them are those of moulds and other innocuous vegetables which have no chance of growing there; and although there is a possibility of an occasional pathogenic organism being among the number, the risk of its developing is so small, that it is now generally considered to be negligible, and that if one or two should escape into the lymph channel, they will never elude the phagocytes in spleen or bone marrow or elsewhere.

I must now explain how the spray helped to prepare Lister for the acceptance of Metchnikoff's discoveries. 
I said it was unpleasant for all. There were some surgeons to whom it was positively poisonous. Amongst these was a friend of Lister's, Thomas Keith, the ovariotomist, whose field of operation was, of course, the peritoneal cavity. In pre-antiseptic days he had obtained results that had astonished the world, by dint of great dexterity, devoted personal attention, and scrupulous regard to cleanliness. His success tried the faith of some, but not of Lister, who was aware of the specially high vitality of the peritoneum, and of other anatomical and physiological peculiarities which diminish the chance of survival of germs, but which are too technical for discussion here.

Keith's success was so great that he hesitated to adopt rigorous antiseptic methods, and Lister at first dissuaded him from doing so, fearing that carbolic acid might dangerously interfere with the vitality of the peritoneum. Besides, at that time he did not fully trust the efficacy of the spray. Keith did, however, for a time use all Lister's methods, including the spray; but this seriously interfered with his health, so he abandoned it, and yet, when he gave it up, his results continued to be as good as when he was using it.

The germicidal powers of the peritoneum are great, but they are only in degree greater than those of muscle, fat, and other tissues. And when it was found that other surgeons, some of them keen disciples, were absolutely forced to give up the spray, or give up surgery, and that, when they chose the former alternative, their results were no worse than before, Lister at last came to the conclusion that the spray was unnecessary, even if it had really made an antiseptic atmosphere, but, as I said before, he now saw that this was impossible. The spray was really only a convenient, unconscious, automatic irrigator. It killed germs on the wound, not in the air, and as such had been very useful during the time when the lesson was being gradually learned that every surgical operation, every surgical dressing, is, in fact, a complicated bacteriological experiment.

The mitigation of the strength of the lotion and the abandonment of the spray seemed to some like lowering the standard. But it was not so. It was not so because the principle remained unshaken, namely, that as organisms are the cause of putrefaction they must be excluded from a wound, or if they had gained access to it they must be destroyed or prevented from growing. Two changes of method had indeed been introduced:-weaker antiseptics were employed because greater respect was paid to the defensive powers of the body, and the spray was given up because opinion had altered with regard to the importance of aerial attacks. Aircraft came to be disregarded, while it was seen that what may be compared to land and water attacks were far more dangerous. The germs on the skin of the patient, the dirt on the hands of the surgeon, the unpurified sponge, the dried clot on a badly cleaned instrument; these were the dreadnoughts and submarines; these were the sappers and miners, the howitzers, and handgrenades that really decided the fate of the campaign. Thus it became obvious that the precautions taken against such sources of danger, which, though they were adopted from the first, had been overshadowed by the attention devoted to the air-raids, were really of far more vital importance; and much ingenuity was thenceforward devoted to devising means for purifying the skin by mechanical or chemical means, to inventing gloves which would not impair the sense of touch, and also to proving that there was a radical difference between aseptic and antiseptic surgery.

We now come to the question of what is meant by aseptic as opposed to antiseptic surgery. Aseptic is no new word. Lister employed it quite early in his writings, and, though it is plain to see why he called his system antiseptic, it is almost to be regretted that he did not call it aseptic. It would have preverited the confusing suggestion that, as Hunter and others had spoken of and used antiseptics, his system was nothing new, and perhaps it might have saved us from the still more confusing suggestion that there is some fundamental antagonism between aseptic and antiseptic treatment, though they are really the same.

Those who call themselves aseptic surgeons main tain that they do not employ chemical antiseptic agencies. The idea started amongst the gynæcologists who, as has been shown, were working under peculiarly favourable conditions as regards asepsis. They were supposed to use only mechanical means in striving after cleanliness-washings and scrubbings and so forth, which do, of course, remove the deadliest form of danger, particulate dirt. But even these surgeons, or some of them, used to employ freely the most potent of all antiseptics, heat. They boiled their instruments and boiled the water with which they washed out the peritoneal cavity, and some were in the habit of using a pretty powerful antiseptic, sulphurous acid for purifying those most dangerous things, sponges.

Let us now watch an aseptic surgeon at work. Somewhere in the background there must be a very large steriliser for superheating overalls, caps, veils, towels, dressings, and bandages; also a boiler for boiling instruments, and an unlimited supply of boiled (he calls it sterilised) water and normal salt solution.

He spends a long time in scrubbing his hands in soap and water, and probably in spirit of wine, which is an antiseptic; he then puts on his sterilised overall, cap, veil, and india-rubber gloves. Thus, converted from a dangerous into a harmless character, he ought never to touch any contaminated object. But it is to be feared that he sometimes forgets the meaning of his vestures: that he wrongly looks upon them as armour, and, inspired by this confidence, he touches the unclean thing, and then puts his fingers into the wound.

One may be forgiven a passing smile at the unreasoning way in which these details are followed out. Surgeons dress themselves up like white-robed priests to examine the external ear, or to explore those parts of the body that no process on earth can render even approximatelv aseptic.

But to return to our aseptic operation. The instruments, having been boiled, are commonly placed in a tray containing boiled water. Why I have never been able to discover. They would be equally safe if used dry. Probably it is only an imitation of Lister's plan of sterilising his instruments in a tray of carbolic acid lotion.

The patient's skin is almost always purified by a chemical antiseptic, sometimes alcohol, but now usually tincture of iodine. The part to be operated on is then surrounded by superheated dry towels, and the operation proceeds. Superheated swabs have replaced marine sponges. No antiseptic is applied to the wound. Plain boiled water or boiled saline solution is used for washing away clots; preferably saline solution, because it does not interfere with the living cells by osmosis as plain water does.

When the operation is over, a dressing of superheated gauze and wool is fixed by a superheated bandage or by plaister. This, of course, only acts as a mechanical filter of dust, but it is now looked upon with reverence, as if it had some other special virtue, and you may see it applied with extraordinary precautions to septic suppurating wounds and kept on for twenty-four hours, regardless of the fact that it

NO. $237 \mathrm{I}$, VOL. 95] 
becomes a septic dressing immediately after application; that it is, in fact, nothing but a beautifully whitened sepulchre full, if not of dead men's bones, at all events of all uncleanness.

Some aseptic surgeons apply their principle to compound fractures and rely solely on mechanical means for removing dirt from the recesses of the wounds; but most, I believe, continue to employ powerful antiseptics for this purpose, and in this class of injury follow Lister's instructions.

I am not so ignorant or bigoted as to suggest that so-called aseptic surgery is a bad way of treating wounds. I know that first-rate results are constantly obtained by means of it. But, I maintain, and here I am repeating what Lister often said to me :-

(r) That it is a troublesome and difficult process, involving for successfully carrying it out an amount of paraphernalia and an amount of training that puts it almost beyond the reach of all except hospital surgeons.

(2) That it is misleading to set it up in opposition to the antiseptic system, because most of its advocates use chemical antiseptics for one purpose or another, and all employ heat with great freedom.

(3) That infections of the skin and consequent later suppuration is more likely to occur than if Lister's methods are followed.

I will now describe one of Lister's operations in his last years at King's College. He did not require a huge autoclave for sterilising. He did not wear gloves, but he purified his own hands and the skin of the patient by a most potent antiseptic, which was called the strong mixture. It consisted of I to 20 carbolic acid in $\mathrm{I}$ to 500 corrosive sublimate. Lister, fortunately or unfortunately, had a very resisting skin; his hands, however, were usually rough; but he did not seem to mind. This was not the case with many of his followers, who could not, or would not, stand the discomfort strong lotions produced. This has undoubtedly been one cause of secession. The instruments and the sponges (he used marine sponges) had been long steeped in strong carbolic acid lotion, but during the operation they were wrung out of a very weak antiseptic solution. The towels placed round the field of operation were also carbolised. No irrigation was carried out. When the operation was complete, a dressing containing an antiseptic substance was applied.

His treatment of compound fractures was never modified after the first few years.

The differences you see are these:-

(I) Lister trusted to a potent chemical antiseptic, instead of to mechanical cleansing and heat, for sterilising the skin, instruments, and the objects likely to be brought into contact with the wound.

(2) $\mathrm{He}$ applied a very weak antiseptic in small amount to the wound itself, instead of boiled water or normal saline solution.

(3) Instead of plain gauze he used an antiseptic dressing, which has the great advantage of acting upon any organisms that, after the operation may reach the surface from the sweat and sebaceous glands of the patient.

These differences between the two systems, as thus stated, do not appear to be great, but they are important. "The little more, and how much it is! and the little less and how far away!" For in one there is simplicity and safety, in the other complication and risk. Thus in the first place sterilising by a chemical antiseptic involves no special apparatus. It can be carried out in the humblest cottage. Secondly, the use of an antiseptic during the operation does away with the necessity of the surgeon and his assistants, voung dressers, or busy country doctors, or nurses being constantly on the qui vive lest their simply aseptic garments should touch some unpurified thing and then convey defilement to the wound. Thirdly, security is provided for against secondary infection from the skin; or secondary infection through the dressing, if the discharges should soak through to the surface and thus supply a neutral track for the germs to travel along.

When I come to speak of results I must necessarily be vague. I have, however, formed the opinion, from much observation and long experience, that the standard as regards suppuration amongst aseptic surgeons is lower than Lister's used to be. If a case "goes wrong," as the common but mischievous expression is, it is looked upon as an unavoidable accident, not as a disgrace. In recent years the term, "stitch abscess," has sprung into use." Lister said he never had stitch abscesses. Forgive me for dwelling on them for a moment. The name is applied to suppurations occurring about stitches, and they arise in this way. Our skin is full of small glands for supplying greasy material to the hairs. Organisms are present in these glands, and any weakening of the tissues gives them a chance of doing mischief, the commonest illustration of which is the ordinary boil that starts from the fretting of a cuff or a collar. A tight stitch, or a not very tight one, may do the same. But the risk is very much diminished by thorough purification of the skin, which is much more effectually obtained by following Lister's instructions than by "aseptic" methods. It may be granted that stitch abscesses do not often lead to serious mischief, but they often cause troublesome suppuration in the wound itself and involve delay, and the removal of important deep stitches, which were intended to be permanent. This risk is also lessened by using an antiseptic as opposed to an aseptic dressing. I confess I have never been able to understand the objection to an antiseptic gauze dressing. If the wound heals by first intention the antiseptic substance cannot possibly act upon the raw surface of the wound. Antiseptic gauze has all the advantages of sterilised gauze except that it is slightly more expensive and has none of its disadvantages; in fact, I am confident that it has only been discarded on purely theoretical grounds.

To what extent, then, should we return? I would not urge the use of marine sponges, because they are difficult to clean and expensive, and because cotton. swabs are equally efficient. Nor would I recommend the giving up of india-rubber gloves, although I know that they have their dangers, and although I know that they may safelv be dispensed with by an antiseptic surgeon. Boiling instruments, I think, should be continued. Otherwise I say that it is only fair to students to tell them, and show them, that by carrying out Lister's technique, it is more easy to obtain the very best results and less likely to fail.

I have only spoken of civil practice, but I would not have ventured to offer you a surgical address, and I could not have hoped to attract your attention if it had had no bearing upon the war which is now raging.

Lister's faithful followers had not only watched with regret what they considered to be a retrograde step in civil practice, but they feared that a war would bring out in relief its weak points.

Wars have occurred of late in distant parts of the world, but we paid little heed to the details. It required a war in our midst, with our own flesh and blood in the trenches exposed to the bullets of the foe, and to the pestilence that walketh in darkness, to bring the matter really home to Englishmen. And when it came, the reports from the front of almost No. $237 \mathrm{I}$, VoL. 95] 
universal sepsis made us fear that our prognostication had come true, and that the abandonment of antiseptics was, at least in part, accountable. It appears, however, that antiseptics are being very largely used, though with most disappointing results. The fact must not be overlooked that military surgery is exceptional, and that this particular war is being fought in most exceptional circumstances--. trenches dug and monster shells exploding in the highly-cultivated soil of a noted tetanus area like the valley of the Aisne. It is almost impossible for us at home to appreciate what is going on. Listen, therefore, to this graphic extract from a letter I received last week from Sir Anthony Bowlby:"In this trench warfare you must remember that, if a man is hit, he often falls into filthy mud and water, which may be $3 \mathrm{ft}$. deep or more. Remember also that the trench is only $2 \frac{1}{2} \mathrm{ft}$. wide. If it is night, you can only grope about in the dark and can do no dressing of any kind, for you can't even get any clothes off in the dark, and in so cramped a space, and you must try to get the man away to a 'dressing station' half a mile distant, and thence to a field ambulance. If it is daylight, you can't get the man out of the trench at all, and he may have to be kept there for many hours, because he would certainly be killed if he was got out of the trench. And the water in the trenches is hopelessly polluted, and soaks his clothes and his wound. It is only too evident that large lacerated wounds, and especially bad bone smashes, are so contaminated that it can never be possible to render them aseptic."

This is a dreadful picture; but all fighting is not trench fighting, and we might have hoped not to be told that all wounds, except bullet wounds, are septic, seeing that a few, at least, come under treatment within a reasonable period, say twelve hours, after infliction.

I have been helping Sir Watson Cheyne to lead a crusade in favour of applying to these dirt-infected wounds Lister's original method of purification by means of undiluted carbolic acid. Not that I advocate it for civil practice, but because I think that the only chance of destroying the organisms of tetanus and gas gangrene, and the best way of dealing with streptococci, is to use the most potent and safest antiseptic which is at the disposal of the surgeon for the purpose.

The suggestion met with the cordial approval of those who, like myself, have employed this agent extensively. But it excited a certain amount of loud criticism from others, who were chiefly impressed by the fact that undiluted carbolic acid produces a certain amount of sloughing. This criticism is easily met, because, if employed with the discretion that may be expected of reasonable people, the slough is unimportant, superficial, and antiseptic-incomparably less suited for the growth of micro-organisms than the extensive and spreading sloughs which they themselves produce. Moreover, these antiseptic sloughs do no harm, but are quickly absorbed if the wound heals antiseptically.

That is not the weak point in the argument. There is, however, another, more difficult to answer, of which our opponents did not make so much. Unfortunately, it cannot be denied that the spores of the bacilli of tetanus resist the action of even undiluted carbolic acid for a very considerable time. Moreover, my colleague, Dr. Thiele, has shown that if easily recognisable micro-organisms are injected into the subcutaneous tissue, they enter the lymph channels, and may pass into the circulation in the course of a fow minutes, long before there is a chance, if the same thing happens in contused wounds, of getting at them with our antiseptics.

No. $237 \mathrm{I}$, VOL. 95$]$
Are we, then, to abandon this line of treatment, to fold our hands in despair and say that it is useless to attempt to disinfect any wound in civil or military practice to which spore-bearing or other organisms may have gained access? By no means. All Lister's work cries out against such a conclusion. We must clear our minds of the delusion that carefully planned experiments on guinea-pigs in the laboratory are on all fours with unrehearsed experiments in factories, or on wounded soldiers in the battlefield. Lister did undoubtedly succeed in stopping sepsis in compound fractures and in banishing tetanus and hospital gangrene from his wards, and the experience of generations of surgeons working with a saturated watery solution of carbolic acid has confirmed his conclusions. Surely, then, it may be possible to find a practical way of applying the principle to military practice.

It will not, however, do to brush the argument aside in this way without examining it and answering it. I therefore submit for your consideration a suggestion as to what happens in a case successfully treated antiseptically, that is, one that heals without suppuration.

We do not know for certain in what form the anaerobic spore-bearing organisms are introduced into a wound. I, at all events, do not know of scientifically conducted observations upon the subject. But it is clear that they must be either in the form of bacteria, or spores, or both, probably embedded in decaying organic matter in the soil. If the antiseptic reaches them it destroys the bacteria, together with the other septic organisms. But possibly, or, let us say, probably, it has not sufficient time before becoming too diluted to kill the spores, though it may for a while inhibit their power of development. There, then, these spores lie dormant between a thin layer of carbolised slough and a mass of more or less carbolised blood clot. If sepsis is avoided, the phagocytes at last invade both the slough and the clot, and healing takes place without suppuration. What is the fate of the spores?

We must suppose that, when the carbolic acid has disappeared, as they are embedded in a warm, airless nidus, they germinate, but only to find themselves surrounded by active phagocytes which, if they form a suitable pabulum, destroy them. And so the matter ends so far as the wound is concerned.

This, I maintain, is a reasonable hypothesis and a sufficient answer, and fortunately it is rare indeed, if it ever happens, for tetanus to occur after a. wound has healed without any suppuration at all ; and, moreover, the abolition of tetanus in civil practice has coincided with the reduction in the number of suppurating wounds.

As a further support of the argument, let us now consider the case of the bacteria and spores of tetanus or gas gangrene lying together in an untreated wound, or in one to which less powerful antiseptics are applied, antiseptics not strong enough to destroy the pus-producing organisms. They find themselves, therefore, amongst extensive septic sloughs and decomposing blood-clots in which the phagocytes, if they can penetrate at all, have their time fully occupied with myriads of other organisms, which first weaken and then overpower them. Is it to be wondered at that lockjaw and gas gangrene affect a certain proportion of such cases? On the contrary, the marvel is that these complications are not more frequent.

For, after all, though tetanus and gas gangrene are ghastly things, and make a great impression because the laity knows about them, these diseases are not by any means the most deadly or the most frequent. Probably 40 per cent. of the wounds at one part of the campaign were infected with tetanus, but, up to 
date, there have been reported only 207 cases, of which only 2 have occurred since January 20 . And it must be remembered that there are effectual ways of dealing with both diseases-tetanus by the prophylactic administration of antitetanic serum, and gas gangrene by very free incisions.

No, the deadliest enemy is the ubiquitous streptococcus, the foe that kills more than shells and bullets. But as it is certainly killed by undiluted carbolic acid or by a 5 per cent. solution in water, there is at least a chance that, so far as streptococci are concerned, wounds may be disinfected even in war, and if these and the other pyogenic organisms are destroyed, there is, as I have shown, great reason to suppose that sporing anaerobes like Bacillus tetani would have no chance of growing. ${ }^{2}$

But it may be said: "What about the organisms that have entered the lymph channel and the blood current? What is the good of trying to purify the wound if they have already given us the slip?"

Let us see precisely what Dr. Thiele says, and remember that his experiments are conducted by injecting cultivations of micro-organisms subcutaneously. He maintains :-

(I) That they travel quickly to the nearest lymphatic glands, where they are retarded, perhaps killed.

(2) If not, they make their way along the thoracic duct to the jugular vein and enter the blood stream, and by that channel are conveyed, a few at a time, not in sufficient numbers to be detected by the microscope, to the bone marrow, the spleen, and other parts where groups of cells of the phagocyte class are ready to deal with them.

(3) If the enemy overpowers all these means of resistance they may invade the blood in large numbers and cause general blood-poisoning.

(4) That some are quickly taken up by the blood without passing through the lymphatics.

I must again point out that, in spite of all these alarming facts, general septicæmia probably never occurs if the wound heals without suppuration. To take another simile from the war, the germs that escape into the circulation are like enemy aliens, prisoners of war, or the struggling Turks who crossed the Suez Canal. It is not they, but the main body on the fighting line-that is, the woundwho are engaged in manufacturing the deadly toxins. If they can be annihilated, there is not much fear of mischief from the enemy in our midst. It has never been suggested that germs which have entered the circulation from the wound go back with their ill-begotten progeny to make it suppurate. The argument, therefore, that it is useless to try to make wounds aseptic because some germs have already escaped into the circulation is no stronger than that founded on the resisting powers of spores to the action of antiseptics. Both are the arguments of the bacteriologist rather than of the practical surgeon, and, whilst being treated with all respect, they must not be estimated above their true value.

I cannot hope that your patience is not exhausted. But I trust that you are now convinced of the real danger that may result from neglecting Lister's teaching both in civil and military practice.

As to the latter, which for the moment occupies almost all our thoughts, I should be the last to say that there is only one way of salvation-that, for example, corrosive sublimate is dangerous, or iodine untrustworthy, or peroxide of hydrogen of little value.

2 In using the word anaerobe I desire to own that I do not completely understand its meaning. It certainly has been used in more than one sense, and to-day bacteriologists are not agreed about the effect of oxygen on anaerobes, their need for it, the sources from which they obtain it, and othe points. We cannot divide micro-urganisms by a clear cut line into aerobes
and anaerobes. NO. 237 I, VOL. 95]
Still less would I say that military and civil surgery should be run on the same lines. But I still think that undiluted carbolic acid is, according to our present lights, the antiseptic most likely to be practically useful in the rough-and-tumble practice of the battlefield.

And whether or not this may turn out to be the conclusion of our gallant brethren at the front, I would add that the experience of the present war is one of the strongest arguments for rallying to Sir James Crichton-Browne's battle-cry, "Back to Lister."

Long ago it was prophesied that science would stop war by making it too horrible. Are we nearing that blessed result? One fact stands out in spite of the faint hopes I have expressed-that nothing can stop sepsis in war except stopping war altogether.

\section{UNIVERSITY AND EDUCATIONAL INTELLIGENCE.}

Cambridge.-Mr. W. L. Mollison has been elected master of Clare College, in succession to the late Dr. E. Atkinson. He was Second Wrangler in the Mathematical Tripos of 1876 , and Second Smith's Prizeman, and was elected a fellow of Clare in that year. Afterwards he became successively junior tutor and senior tutor, and was at one time moderator and examiner in the Mathematical Tripos. He was made an Honorary LL.D. of the University of Aberdeen in 1897 .

London.-Mr. L. W. King, assistant keeper of the Egyptian and Assyrian department of the British Museum, has been elected professor of Assyrian and Babylonian archæology at King's College. Mr. King's professorship will be a part-time post, and he will retain his position at the museum.

Dr. F. Wood-Jones, lecturer and head of the department of anatomy at the London (Royal Free Hospital) School of Medicine for Women, has been granted the title of professor of anatomy in the University.

WE learn from Science that Robert Flersheim has left a bequest of a million marks to the University of Frankfurt.

THE Rockefeller Foundation has, says Science, made comprehensive plans for improving medical and hospital conditions in China. The plans are based on the report of the special commission sent by the foundation to China. To carry out this work the foundation has established a special organisation to be called the China Medical Board of the Rockefeller Foundation, of which Mr. J. D. Rockefeller, jun., is chairman. The plan outlined by the commission provides for the development of medical education in China as the first step. With the view of building up a body of Chinese medical men able to teach medical science, the foundation has decided to establish six fellowships, each of $200 l$. a year and travelling expenses, to enable Chinese graduates to study abroad. Six fellows have been appointed, one of whom is already studying in the United States.

THE new buildings of the Mellon Institute of Industrial Research and School of Specific Industries of the University of Pittsburgh were formally opened on February 26 last. The institute, which cost $75,000 l$., was the gift of Messrs. A. W. and R. B. Mellon, of Pittsburgh; it is provided with complete facilities for the investigation of manufacturing problems and for conducting industrial research in accordance with the system of co-operation between science and industry, founded by the late director of the institute, Dr. R. K. Duncan. By this system, a manufacturer having a 